\title{
PERAN KOMITMEN ORGANISASIONAL MEMEDIASI PENGARUH KEPUASAN KERJA TERHADAP TURNOVER INTENTION
}

\author{
I Wayan Bagus Satya Utama1 \\ Ida Bagus Ketut Surya ${ }^{2}$ \\ ${ }^{1,2}$ Fakultas Ekonomi dan Bisnis Universitas Udayana, Bali, Indonesia \\ email: satya.utamaa@gmail.com
}

\begin{abstract}
ABSTRAK
Tujuan penelitian ini yaitu (1) Untuk menjelaskan pengaruh kepuasan kerja terhadap turnover intention, (2) Untuk menjelaskan pengaruh komitmen organisasional terhadap turnover intention, (3) Untuk menjelaskan pengaruh kepuasan kerja terhadap komitmen organisasional, (4) Untuk menjelaskan peran mediasi komitmen organisasional pada pengaruh kepuasan kerja terhadap turnover intention. Populasi penelitian ini adalah karyawan PT Cipta Nirwana. Teknik pengambilan sampel menggunakan simple random sampling dengan jumlah sampel sebanyak 47 responden. Teknik analisis yang digunakan yaitu teknik analisis jalur (path analysis). Penelitian ini membuktikan bahwa (1) Kepuasan kerja berpengaruh negatif dansignifikan terhadap turnover intention, (2) Komitmen organisasional berpengaruh negatif dan signifikan terhadap turnover intention, (3) Kepuasan kerja berpengaruh positif dan signifikan terhadap komitmen organisasional, (4) Komitmen organisasional secara parsial memediasi pengaruh kepuasan kerja terhadap turnover intention.
\end{abstract}

Kata kunci: turnover intention, komitmen organisasional, kepuasan kerja

\section{ABSTRACT}

The purpose of this study are (1) To explain the effect of job satisfaction on turnover intention, (2) To explain the effect of organizational commitment on turnover intention, (3) To explain the effect of job satisfaction on organizational commitment, (4) To explain the mediating role of organizational commitment the effect of job satisfaction on turnover intention. The population of this research is the employees of PT Cipta Nirwana. The sampling technique uses simple random sampling with a total sample of 47 respondents. The analysis technique used is the path analysis technique (path analysis). This study proves that (1) job satisfaction has a negative and significant effect on turnover intention, (2) organizational commitment has a negative and significant effect on turnover intention, (3) job satisfaction has a positive and significant effect on organizational commitment, (4) organizational commitment partially mediates the effect of job satisfaction on turnover intention.

Keywords: turnover intention, organizational commitment, job satisfaction 


\section{PENDAHULUAN}

Sumber daya manusia merupakan hal yang sangat penting bagi sebuah organisasi maupun perusahaan karena keberhasilan suatu organisasi maupun perusahaan dalam mencapai tujuannya sangat dipengaruhi oleh kualitas sumber daya manusia yang ada di dalamnya. Sumber daya manusia seringkali menjadi salah satu faktor penentu eksistensi perusahaan tempatnya bernaung, sehingga perusahaan tidak lagi memandang sumber daya manusia sebagai beban perusahaan, melainkan harus dipandang sebagai aset penting perusahaan. Karena sumber daya manusia merupakan satu-satunya aset perusahaan yang dapat menggerakan sumber daya lainnya. Hal tersebutlah yang membuat perusahaan sadar akan nilai investasi karyawan sebagai sumber daya manusia.

Tenaga kerja yang cakap dan mampu untuk berkinerja baik sangat sulit didapatkan karena perusahan harus mengeluarkan biaya yang cukup tinggi, terlebih lagi untuk mempertahankan yang sudah ada agar tidak keluar dari perusahaan. Perpindahan karyawan (employee turnover) merupakan salah satu fenomena yang sering terjadi dalam perusahaan. Disinilah dituntut adanya peran dari manajemen sumber daya manusia (MSDM) untuk meminimalisir tingkat turnover karyawan. Turnover dapat diartikan sebagai pengunduran diri permanen dari perusahaan baik secara sukarela maupun tidak (Tripathi dan Pandey, 2017). Turnover karyawan dapat menimbulkan biaya yang tinggi dari adanya penggantian karyawan seperti biaya rekrutmen dan seleksi, tingginya tingkat turnover tidak baik bagi perusahaan sehingga perusahaan harus mampu mempertahankan karyawannya dan secara tidak langsung dapat menghemat biaya (Saeed et al., 2014).

Penelitian ini dilakukan di PT Tiara Cipta Nirwana, yang merupakan sebuah perusahaan Holding (Graha Dewata Holding Company) yang bergerak di bidang MEP (Mechanical, Electrical, Plumbing) dan SWRO (Sea Water Reverse Osmosis). PT Tiara Cipta Nirwana dalam menjalankan operasionalnya, memerlukan sumber daya manusia dalam jumlah yang banyak. Data jumlah karyawan dan data turnover karyawan tahun 2015-2018 PT Tiara Cipta Nirwana dapat dilihat pada Tabel 1.

Tabel 1.

Turnover Karyawan PT Tiara Cipta Nirwana Tahun 2015-2018

\begin{tabular}{cccccc}
\hline Tahun & $\begin{array}{c}\text { Jumlah } \\
\text { Karyawan } \\
\text { Awal } \\
\text { Periode } \\
(\mathbf{1})\end{array}$ & $\begin{array}{c}\text { Jumlah } \\
\text { Karyawan } \\
\text { Akhir } \\
\text { Periode } \\
(\mathbf{2})\end{array}$ & $\begin{array}{c}\text { Karyawan } \\
\text { Masuk } \\
\mathbf{( 3 )}\end{array}$ & $\begin{array}{c}\text { Karyawan } \\
\text { Keluar } \\
\mathbf{( 4 )}\end{array}$ & $\begin{array}{c}\text { Turnover } \\
\text { Karyawan } \\
(\mathbf{5})= \\
(\mathbf{4})\end{array}$ \\
& 85 & 72 & 38 & 51 & 64,9 \\
$\mathbf{2 0 1 5}$ & 72 & 75 & 12 & 9 & 12,2 \\
$\mathbf{2 0 1 6}$ & 75 & 77 & 21 & 19 & 25,0 \\
$\mathbf{2 0 1 7}$ & 77 & 90 & 33 & 20 & 23,9 \\
$\mathbf{2 0 1 8}$ & &
\end{tabular}

Sumber: Human Resource Development PT Tiara Cipta Nirwana, 2019

Berdasarkan Tabel 1. menunjukkan bahwa tingkat turnover karyawan PT Tiara Cipta Nirwana tahun 2015-2018 jauh diatas 10 persen. Hasil wawancara dengan pihak human resource development PT Tiara Cipta Nirwana didapatkan 
bahwa karyawan yang keluar dari perusahaan disebabkan karena karyawan tidak merasa puas terhadap pekerjaannya, hal tersebut disebabkan karena pada tahun 2014 PT Tiara Cipta Nirwana menerapkan manajemen mutu yang berbasis teknologi sistem informasi yang terintegrasi. Karyawan yang pada awalnya dapat menunda pekerjaan harus melaporkan hasil pekerjaannya setiap hari, dengan demikian karyawan tidak lagi dapat menunda pekerjaannya. Perubahan tersebut menyebabkan banyak karyawan yang malas tidak dapat mengikuti sistem kerja baru yang diterapkan oleh PT Tiara Cipta Nirwana. Menurut Fahrizal dan Utama (2017) turnover diatas $10 \%$ dalam satu tahun dapat mengganggu kinerja perusahaan. Tingginya tingkat turnover mengindikasikan adanya tingkat turnover intention yang tinggi pula.

Turnover intention adalah sebuah keinginan karyawan untuk meninggalkan perusahaan karena niat untuk pindah ke lain perusahaan (Pariatiningsih dan Utama, 2015; Kusuma dan Mujiati, 2017). Menurut Busari et al. (2017) jam kerja yang tidak sesuai dengan ketentuan, kebijakan pengembangan karir yang tidak jelas, gaji yang tidak sesuai, dan hubungan karyawan dengan atasannya yang tidak baik, beberapa hal tersebut dapat menimbulkan turnover intention. Mengidentifikasi penyebab dari turnover intention memberikan sedikit bayangan dalam memahami turnover karyawan dalam perusahaan (Salleh et al., 2012). Tripathi dan Pandey (2017) menjelaskan bahwa turnover intention berpengaruh secara positif terhadap turnover. Hal tersebut menunjukkan bahwa dengan semakin tingginya keinginan karyawan untuk pindah, maka semakin besar pula tingkat turnover karyawan yang akan terjadi.

Perusahaan harus menerapkan langkah-langkah yang tepat dalam melakukan penepatan karyawan agar karyawan merasa puas dengan pekerjaannya dan memandang pekerjaan sehari-hari karyawan layak sepanjang waktu, hal tersebut dapat mengurangi keinginan karyawan untuk keluar atau berpindah dari perusahaan (Azeez et al., 2016). Tingginya turnover intention diduga disebabkan oleh faktor kepuasan kerja dan komitmen organisasional yang terbilang rendah. Hal ini didukung oleh penelitian yang dilakukan Tnay et al. (2013) dan Hidayat (2018) yang menyatakan bahwa turnover intention sangat terkait dengan kepuasan kerja dan komitmen organisasional.

Kepuasan kerja didefinisikan sebagai suatu perasaan positif karyawan tentang pekerjaannya (Robbins dkk., 2006:40). Menurut Tripathi dan Pandey (2017) jika kemampuan dan kapabilitas karyawan tidak cocok dengan job description, maka itu akan mengakibatkan ketidakpuasan. Karyawan yang memiliki ketidakpuasan atas pekerjaannya akan menimbulkan beberapa masalah bagi perusahaan, seperti kinerja yang buruk, sering meninggalkan pekerjaan dan memiliki semangat kerja yang rendah, apabila perusahaan tidak memperhatikan kepuasan kerja karyawan hal tersebut akan memicu timbulnya turnover intention (Andini dkk., 2018). Salleh et al. (2012) dan Hidayat (2018) menyebutkan indikator dari kepuasan kerja adalah gaji, pengembangan karir, rekan kerja, pekerjaan itu sendiri dan pengawasan atasan.

Selain kepuasan kerja, rendahnya tingkat komitmen organisasional juga menyebabkan tingginya turnover intention (Satrio dan Surya, 2018). Komitmen organisasi adalah keadaan seorang karyawan memihak kepada perusahaan 
tempatnya bekerja dan keinginannya untuk mempertahankan keanggotaan dalam perusahaan tersebut (Novarinda dan Iqbal, 2017). Keuntungan bagi pihak perusahaan memiliki karyawan yang berkomitmen tinggi adalah adanya peningkatan masa kerja karyawan, tingkat kepuasan kerja yang tinggi dan penurunan angka turnover (Azeem, 2010). Komitmen organisasional merupakan sikap yang mencerminkan loyalitas karyawan kepada perusahaan dan karyawaan memberikan perhatiannya kepada perusahaan untuk keberhasilan serta kemajuannya (Mira dan Margaretha, 2012). Perilaku pimpinan yang memperkenalkan rasa kebersamaan terhadap karyawan dan mengajak karyawan berpartisipasi dalam proses pengambilan keputusan perusahaan akan meningkatkan komitmen organisasional karyawan, peningkatan tersebut ditandai dengan meningkatnya rasa ikatan emosional karyawan dengan perusahaan tempatnya bekerja dan meningkatnya loyalitas karyawan terhadap perusahaan sehingga bersedia untuk tetap bertahan pada perusahaan tersebut (Kamanjaya dkk., 2017).

Penelitian yang dilakukan Rekha dan Kamalanabhan (2010), menjelaskan bahwa yang dapat membantu karyawan meningkatkan komitmen karyawan terhadap organisasi adalah dengan meningkatkan kepuasan kerja karyawan, ketika komitmen terhadap organisasi meningkat, niat karyawan untuk berhenti dari tempat kerjanya akan menurun, sehingga dapat dikatakan komitmen organisasional memediasi hubungan kepuasan kerja terhadap turnover intetntion. Menurut penelitian yang dilakukan (Tarigan dan Ariani, 2015) yang menyatakan bahwa karyawan yang memiliki tingkat kepuasan yang tinggi akan meningkatkan komitmen organisasionalnya sehingga menurunkan niat untuk keluar atau berpindah dari perusahaannya saat ini.

Karyawan yang merasa terpuaskan dengan pekerjaannya cenderung untuk bertahan dalam perusahaan, sedangkan karyawan yang merasa kurang terpuaskan dengan pekerjaannya akan memilih keluar dari perusahaan. Kepuasan kerja yang dirasakan dapat memengaruhi pemikiran seseorang untuk keluar. Hal tersebut didukung oleh penelitian yang dilakukan Saeed et al. (2014) yang menyatakan ada hubungan negatif antara hubungan kepuasan kerja dengan turnover intention, semakin tinggi selisih antara ekspektasi karyawan terhadap imbalan yang akan diterima dengan imbalan yang benar-benar diterima maka hasilnya akan meningkatkan turnover intention karyawan.

Andini dkk. (2018) dalam penelitiannya mengemukakan variabel kepuasan kerja berpengaruh secara negatif dan signifikan terhadap turnover intention, semakin tinggi tingkat kepuasan kerja yang dirasakan karyawan, maka tingkat untuk keluar atau berpindah akan menurun. Hasil yang sama juga diperoleh dari penelitian yang dilakukan Yücel (2012; Alniaçik et al., (2013); Huang dan Su (2016); Tripathi dan Pandey (2017); Hidayat (2018) yang menjelaskan bahwa meningkatnya kepuasan kerja karyawan maka akan menurunkan keinginan karyawan untuk keluar dari perusahaannya. Berdasarkan sejumlah penelitian tersebut, maka dapat dirumuskan hipotesis sebagai berikut.

$\mathrm{H}_{1}$ : Kepuasan kerja berpengaruh negatif terhadap turnover intention 
I Wayan Bagus Satya Utama, Peran Komitmen Organisasional...

Komitmen organisasional dikatakan menjadi variabel yang penting jika membicarakan turnover intention hal itu dikarenakan suatu kepercayaan bahwa karyawan lebih berkomitmen kepada perusahaannya, sehingga semakin kecil kemungkinan karyawan akan meninggalkan perusahaan atau berpindah ke perusahaan lain. Pernyataan tersebut didukung oleh penelitian yang dilakukan Perryer et al. (2010) yang menjelaskan bahwa affective commitment dan continuance commitment berpengaruh secara negatif dan signifikan terhadap turnover intention.

Hal yang hampir sama dijelaskan oleh Wong dan Wong (2017) dan Islam et al. (2015), bahwa affective commitment berpengaruh negatif dan signifikan terhadap turnover intention. Kusuma dan Mujiati (2017) menyatakan bahwa komitmen organisasional memiliki pengaruh negatif dan signifikan terhadap turnover intention, berarti apabila karyawan memiliki keinginan berkorban yang tinggi untuk memberikan kontribusinya bagi perusahaan maka tingkat keinginan untuk keluar dari perusahaan akan menurun. Berdasarkan sejumlah penelitian tersebut, maka dapat dirumuskan hipotesis sebagai berikut.

$\mathrm{H}_{2}$ : Komitmen organisasional berpengaruh negatif terhadap turnover intention

Menurut Azeem (2010; Yücel (2012); Tarigan dan Ariani (2015), menyatakan bahwa kepuasan kerja berperngaruh positif dan signifikan terhadap komitmen organisasional, dapat dikatakan bahwa semakin tinggi tingkat kepuasan yang dirasakan karyawan terhadap pekerjaannya, maka akan meningkatkan komitmen organisasionalnya.

Hal tersebut sejalan dengan penelitian yang dilakukan Babalola (2016); Hidayat (2018) yang menjelaskan bahwa kepuasan kerja berpengaruh positif terhadap komitmen organisasi. Valaei dan Rezaei (2016) menjelaskan hubungan kepuasan kerja terhadap komitmen organisasional dengan mencari hubungan antara masing-masing dimensi kepuasan kerja dan komitmen organisasional, didapatkan kesempatan promosi dan pekerjaan itu sendiri memiliki pengaruh positif dan signifikan terhadap affective commitment, continuance commitment, dan normative commitment; rekan kerja berpengaruh positif terhadap affective commitment; gaji berpengaruh positif dan signifikan terhadap affective commitment dan continuance commitment; dan pengawasan (supervisi) berpengaruh positif signifikan terhadap normative commitment. Seluruh dimensi kepuasan kerja memiliki pengaruh yang positif terhadap komitmen organisasional namun tidak semua signifikan. Berdasarkan sejumlah penelitian tersebut, maka dapat dirumuskan hipotesis sebagai berikut.

$\mathrm{H}_{3}$ : $\quad$ Kepuasan kerja berpengaruh positif terhadap komitmen organisasional

Karyawan yang memiliki tingkat kepuasan yang tinggi akan meningkatkan komitmen organisasionalnya sehingga menurunkan niat untuk keluar atau berpindah dari perusahaannya saat ini. Hal tersebut didukung oleh Tarigan dan Ariani (2015), dalam penelitiannya menjelaskan bahwa multidimensi dari komitmen organisasional yaitu: affective commitment, continuance commitment, dan normative commitment memediasi pengaruh kepuasan kerja terhadap turnover intention. Kepuasan kerja dan komitmen organisasional memiliki pengaruh terhadap turnover intention, tapi pengaruh komitmen organisasional lebih kuat terhadap turnover intention karyawan. 
Penelitian yang dilakukan Rekha dan Kamalanabhan (2010) menjelaskan bahwa yang dapat membantu karyawan meningkatkan komitmen karyawan terhadap organisasi adalah dengan meningkatkan kepuasan kerja karyawan, ketika komitmen terhadap organisasi meningkat, niat karyawan untuk berhenti dari tempat kerjanya akan menurun, sehingga dapat dikatakan komitmen organisasional memediasi hubungan kepuasan kerja terhadap turnover intetntion. Hasil yang sama juga diperoleh Rismawan dkk. (2014); Satrio dan Surya (2018), bahwa komitmen organisasional memediasi hubungan antara kepuasan kerja dengan turnover intention. Berdasarkan sejumlah penelitian tersebut, maka dapat dirumuskan hipotesis sebagai berikut.

$\mathrm{H}_{4}$ : Komitmen organisasional memediasi hubungan kepuasan kerja dengan

\section{turnover intention}

Traditional turnover theory menggambarkan perilaku karyawan yang dapat diambil melalui faktor sikap pekerjaan yaitu kepuasan kerja. Menurut Zhao dan Liu, (2010) traditional turnover theory menyatakan bahwa apabila karyawan yang memiliki kepuasan kerja yang tinggi maka karyawan tersebut diyakini tidak akan meninggalkan suatu organisasi. Oleh karena itu, traditional turnover theory mengemukakan bahwa karyawan yang puas dengan apa yang diberikan oleh organisasinya cenderung memiliki komitmen organisasional yang lebih tinggi dan niat keluar dari perusahaan untuk memilih perusahaan lain yang lebih rendah.

Turnover intention merupakan keinginan karyawan untuk meninggalkan perusahaannya dan mencari pekerjaan baru (Azeez et al., 2016). Turnover dapat berupa pengunduran diri, pemberhentian atau kematian anggota organisasi. Busari et al. (2017), menjelaskan bahwa turnover dapat terjadi secara sukarela (voluntary turnover) maupun secara tidak sukarela (involuntary turnover). Voluntary turnover dapat dikatakan keadaan dimana karyawan meninggalkan perusahaan secara sukarela karena merasa tidak puas dengan pekerjaannya. Sedangkan involuntary turnover adalah pemecatan yang merupakan keputusan perusahaan untuk menghentikan hubungan kerja atau kematian karyawan, hal tersebut bersifat uncontrollable bagi karyawan yang mengalaminya.

Karyawan yang merasa terpuaskan dengan pekerjaannya cenderung untuk bertahan dalam perusahaan, sedangkan karyawan yang merasa kurang terpuaskan dengan pekerjaannya akan memilih keluar dari perusahaan. Kepuasan kerja yang dirasakan dapat memengaruhi pemikiran seseorang untuk keluar. Hal tersebut didukung oleh penelitian yang dilakukan Saeed et al. (2014) yang menyatakan ada hubungan negatif antara hubungan kepuasan kerja dengan turnover intention, semakin tinggi selisih antara ekspektasi karyawan terhadap imbalan yang akan diterima dengan imbalan yang benar-benar diterima maka hasilnya akan meningkatkan turnover intention karyawan.

Tingkat turnover adalah kriteria yang cukup baik untuk mengukur stabilitas yang terjadi di perusahaan, dan juga bisa mencerminkan kinerja dari perusahaan. Tinggi rendahnya turnover karyawan pada perusahaan berdampak pula pada tinggi rendahnya biaya perekrutan, seleksi dan pelatihan yang harus di keluarkan perusahaan (Saeed et al., 2014).

Turnover intention menggambarkan pikiran karyawan untuk keluar mencari pekerjaan di tempat lain, atau keinginan meninggalkan perusahaan (Soleimani dan 
Einolahzadeh, 2017). Hal tersebut didukung oleh Andini dkk (2018) bahwa keinginan karyawan untuk keluar dari perusahaan dipicu oleh rasa ketidakpuasan yang dirasakan seperti penghasilan rendah atau dirasakan kurang memadai, kondisi kerja yang kurang memuaskan, hubungan yang tidak baik dengan atasan maupun dengan rekan kerja, serta pekerjaan yang tidak sesuai.

Komitmen organisasional merupakan ikatan afektif terhadap organisasi sebagai akibat dari karyawan membagikan nilai-nilai yang dimiliki organisasi, keinginan karyawan untuk tetap menjadi bagian dari perusahaan dan kesediaan karyawan untuk mengerahkan upaya atas nama perusahaan (Yücel, 2012). Komitmen organisasi adalah keadaan seorang karyawan memihak kepada perusahaan tempatnya bekerja dan keinginannya untuk mempertahankan keanggotaan dalam perusahaan tersebut (Novarinda dan Iqbal, 2017). Azeem (2010) menyebutkan bahwa komitmen organisasional keadaan psikologis yang mencirikan hubungan karyawan dan organisasi dengan implikasinya terhadap keputusan untuk tetap menjadi bagian dari organisasi. Komitmen organisasional mengacu kepada kesiapan karyawan bekerja keras untuk kepentingan organisasi; menerima dan mewujudkan tujuan organisasi, standar organisasi, prinsip organisasi, etika organisasi dan nilai-nilai organisasi; dan tetap menjadi bagian organisasi dalam segala situasi dan kondisi (Mohamed dan Anisa, 2012).

Perilaku pimpinan yang memperkenalkan rasa kebersamaan terhadap karyawan dan mengajak karyawan berpartisipasi dalam proses pengambilan keputusan perusahaan akan meningkatkan komitmen organisasional karyawan, peningkatan tersebut ditandai dengan meningkatnya rasa ikatan emosional karyawan dengan perusahaan tempatnya bekerja dan meningkatnya loyalitas karyawan terhadap perusahaan sehingga bersedia untuk tetap bertahan pada perusahaan tersebut (Kamanjaya dkk., 2017). Karyawan dengan affective commitment yang tinggi akan tinggal di organisasi karena keinginan, karyawan dengan continuance commitment yang tinggi akan tinggal di organisasi karena kebutuhan, sedangkan karyawan dengan normative commitment yang tinggi akan tinggal di organisasi karena keharusan (Satwari dkk., 2016).

Kepuasan kerja karyawan dalam suatu perusahaan memiliki arah negatif pada turnover intention. Semakin puas karyawan akan pekerjaannya, maka keinginan untuk meninggalkan perusahaan semakin kecil. Karyawan yang memiliki kepercayaan untuk berkomitmen pada suatu perusahaan cenderung memiliki keinginan yang kecil untuk meninggalkan perusahaan. Kepuasan kerja yang dimiiki karyawan memiliki pengaruh positif pada komitmen organisasional. Semakin karyawan merasa puas akan pekerjaannya, maka semakin tinggi komitmen karyawan terhadap perusahaan tersebut. Tingkat kepuasan kerja karyawan dipengaruhi secara tidak langsung oleh komitmen organisasional terhadap turnover intention. Semakin tinggi tingkat kepuasan kerja karyawan akan meningkatkan komitmen organisasional yang secara tidak langsung akan menurunkan niat karyawan untuk keluar dari perusahaan.

\section{METODE PENELITIAN}


Penelitian ini dilakukan di PT Tiara Cipta Nirwana yang beralamat di Jl. LC. Gatot Subroto Barat No. 3 Kerobokan Kaja, Kuta Utara, Badung-Bali. Pemilihan lokasi penelitian ini didasarkan karena adanya fenomena turnover karyawan di perusahaan tersebut. Hal ini bisa dijadikan indikasi bahwa terdapat permasalahan mengenai turnover intention. Obyek penelitian yang digunakan dalam penelitian kali ini adalah kepuasan kerja (X), komitmen organisasional (Z), dan turnover intention (Y).

Populasi dalam penelitian ini adalah seluruh karyawan PT Tiara Cipta Nirwana yang berjumlah 90 orang. Metode penentuan sampel yang digunakan dalam penelitian ini yaitu simple random sampling. Menurut Sugiyono (2017:82), simple random sampling adalah pengambilan anggota sampel dari populasi yang dilakukan secara acak tanpa memperhatikan strata yang ada dalam populasi itu. Dalam menentukan jumlah sampel dari sebuah populasi, peneliti menggunakan rumus Slovin, yaitu:

$n=\frac{\mathrm{N}}{1+N e^{2}}$

Keterangan:

$n=$ Ukuran sampel

$\mathrm{N}=$ Jumlah Populasi

$\mathrm{e}=$ Batas toleransi kesalahan sebesar 0,1

Jumlah populasi PT Tiara Cipta Nirwana berjumlah 90 orang, sehingga:

$$
n=\frac{90}{1+90(0.1)^{2}}=47,36
$$

Berdasarkan rumus slovin jumlah sampel yang di dapat 47,36 dibulatkan menjadi 47 responden.

Analisis jalur digunakan untuk menganalisis pola hubungan antar variabel dengan tujuan untuk mengetahui pengaruh langsung maupun tidak langsung variabel eksogen terhadap variabel endogen. Dasar perhitungan koefisian jalur adalah analisis korelasi dan regresi dan dalam perhitungannya menggunakan software dengan program SPSS for windows.

Persamaan Sub-struktural 1

$$
\mathrm{Z}=\beta_{1} \mathrm{X}+\mathrm{e}_{1}
$$

Persamaan Sub-struktural 2

$$
\mathrm{Y}=\beta_{2} \mathrm{X}+\beta_{3} \mathrm{Z}+\mathrm{e}_{2}
$$

Keterangan :

$\mathrm{Y}=$ turnover intention

$\mathrm{X} \quad=$ kepuasan kerja

$\mathrm{Z} \quad=$ komitmen organisasional

$\beta_{1}, \beta_{2}, \beta_{3}=$ koefisien regresi variabel 


$$
\text { e } \quad=\text { error }
$$

Pengujian hipotesis mediasi dapat dilakukan dengan Uji Sobel (Sobel Test). Uji sobel digunakan untuk menguji kekuatan pengaruh tidak langsung variabel kepuasan kerja (X) ke variabel turnover intention (Y) melalui variabel komitmen organisasional $(\mathrm{Z})$. Pengaruh tidak langsung kepuasan kerja $(\mathrm{X})$ terhadap variabel turnover intention $(\mathrm{Y})$ melalui variabel komitmen organisasional $(\mathrm{Z})$ dihitung dengan mengalikan koefisien jalur $X$ terhadap $Z$ (a) dengan koefisien jalur $Z$ terhadap Y (b) atau ab. Standard error koefisien a dan b ditulis dengan $\mathrm{S}_{\mathrm{a}}$ dan $\mathrm{S}_{\mathrm{b}}$, besarnya standard error tidak langsung (indirect effect) $\mathrm{S}_{\mathrm{ab}}$ dihitung dengan rumus dibawah ini:

$$
S a b=\sqrt{b^{2} S a^{2}+a^{2} S b^{2}+S a^{2} S b^{2}}
$$

Untuk menguji signifikansi pengaruh tidak langsung, maka dapat dilakukan dengan menghitung $t$ dari koefisien ab dengan rumus sebagai berikut:

$$
\mathrm{Z}=\frac{a b}{\mathrm{Sab}}
$$

\section{HASIL DAN PEMBAHASAN}

Model regresi dikatakan model yang baik digunakan, apabila model tersebut bebas dari asumsi klasik statistik. Uji asumsi klasik yang dilakukan dalam penelitian ini terdiri dari uji normalitas, uji multikolinieritas, dan uji heteroskedastisitas.

Uji normalitas pada penelitian ini dilakukan dengan menggunakan uji Kolmogorov Smirnov di mana data yang berdistribusi normal jika Asymp Sig.(2tailed) lebih besar dari 0,05 .

Tabel 2.

Hasil Uji Normalitas Struktur 1

\begin{tabular}{lc}
\hline & Unstandardized Residual \\
\hline $\mathrm{N}$ & 47 \\
Kolmogorov-Smirnov & 1,180 \\
Asymp Sig. (2-tailed) & 0,123 \\
\hline
\end{tabular}

Sumber: Data diolah, 2019

Tabel 2. menunjukkan bahwa nilai Kolmogorov-Smirnov sebesar 1,180 sedangkan nilai Asymp Sig.(2-tailed) sebesar 0,123. Hasil tersebut menunjukkan bahwa model persamaan regresi tersebut berdistribusi normal karena nilai Asymp Sig.(2-tailed) lebih besar dari $\alpha=0,05$.

Tabel 3. menunjukkan bahwa nilai Kolmogorov-Smirnov sebesar 0,777 sedangkan nilai Asymp Sig.(2-tailed) sebesar 0,582. Hasil tersebut menunjukkan bahwa model persamaan regresi tersebut berdistribusi normal karena nilai Asymp Sig.(2-tailed) lebih besar dari $\alpha=0,05$. 
Tabel 3.

Hasil Uji Normalitas Struktur 2

\begin{tabular}{lc}
\hline & Unstandardized Residual \\
\hline $\mathrm{N}$ & 47 \\
Kolmogorov-Smirnov & 0,777 \\
Asymp Sig. (2-tailed) & 0,582 \\
\hline Sumber: Data diolah, 2019 &
\end{tabular}

Uji ini digunakan untuk mengetahui ada atau tidaknya penyimpangan asumsi klasik multikolinieritas, yaitu adanya hubungan linier antar variabel eksogen dalam model regresi. Adanya multikolinieritas dapat dilihat dari nilai tolerance atau VIF. Jika nilai tolerance lebih dari 10 persen atau VIF kurang dari 10, maka dikatakan tidak ada multikolinieritas.

Tabel 4.

Hasil Uji Multikolinieritas

\begin{tabular}{lcc}
\hline \multicolumn{1}{c}{ Variabel } & Tolerance & VIF \\
\hline Stres Kerja & 0,334 & 2,995 \\
Kepuasan Kerja & 0,334 & 2,995 \\
\hline
\end{tabular}

Sumber: Data diolah, 2019

Tabel 4. menunjukkan bahwa nilai tolerance dan VIF dari variabel kepuasan kerja dan komitmen organisasional menunjukkan nilai tolerance untuk setiap variabel lebih besar dari 10 persen dan nilai VIF lebih kecil dari 10 yang berarti model persamaan regresi bebas dari multikolinieritas.

Uji ini digunakan untuk menguji apakah dalam model regresi terjadi ketidaksamaan varian dari residual satu pengamatan ke pengamatan yang lain. Jika nilai signifikansinya di atas 0,05 maka tidak mengandung gejala heteroskedastistas.

Tabel 5.

Hasil Uji Heteroskedastisitas Struktur 1

\begin{tabular}{|c|c|c|c|c|c|c|}
\hline \multirow[b]{2}{*}{ Model } & & \multicolumn{2}{|c|}{$\begin{array}{l}\text { Unstandardized } \\
\text { Coefficients }\end{array}$} & \multirow[t]{2}{*}{$\begin{array}{c}\text { Standardized } \\
\text { Coefficients }\end{array}$} & \multirow[b]{2}{*}{$\mathbf{t}$} & \multirow[b]{2}{*}{ Sig. } \\
\hline & & B & $\begin{array}{c}\text { Std. } \\
\text { Error }\end{array}$ & & & \\
\hline 1 & (Constant) & 0,719 & 0,269 & & 2,675 & 0,010 \\
\hline & Kepuasan Kerja & $-0,112$ & 0,065 & $-0,251$ & $-1,740$ & 0,089 \\
\hline
\end{tabular}

Sumber: Data diolah, 2019

Tabel 5. menunjukkan bahwa nilai signifikansi dari variabel kepuasan kerja sebesar 0,089. Nilai tersebut lebih besar dari 0,05 yang berarti tidak terdapat pengaruh antara variabel bebas. Dengan demikian, model penelitian ini tidak mengandung gejala heteroskedastisitas.

Tabel 6. menunjukkan bahwa nilai signifikansi dari variabel kepuasan kerja sebesar 0,128 dan dari variabel komitmen organisasional sebesar 0,705. Nilai tersebut lebih besar dari 0,05 yang berarti tidak terdapat pengaruh antara variabel bebas. Dengan demikian, model penelitian ini tidak mengandung gejala heteroskedastisitas. 
Tabel 6.

Hasil Uji Heteroskedastisitas Struktur 2

\begin{tabular}{clccccc}
\hline & & \multicolumn{2}{c}{$\begin{array}{c}\text { Unstandardized } \\
\text { Coefficients } \\
\text { Model }\end{array}$} & Standardized & & \\
Coefficients & & \\
\hline 1 & & B & Error & Beta & t & Sig. \\
\hline & (Constant) & 0,535 & 0,104 & & 5,172 & 0,000 \\
& Kepuasan Kerja & $-0,065$ & 0,042 & $-0,364$ & $-1,552$ & 0,128 \\
& Komitmen & $-0,015$ & 0,040 & $-0,089$ & $-0,381$ & 0,705 \\
\hline & Organisasional & $-0,040$ &
\end{tabular}

Sumber: Data diolah, 2019

Perhitungan koefisien path dilakukan dengan analisis regresi melalui software SPSS 17.0 for Windows, diperoleh hasil yang ditunjukkan sebagai berikut.

Tabel 7.

Hasil Analisis Jalur Persamaan Regresi 1

\begin{tabular}{|c|c|c|c|c|c|}
\hline \multirow[t]{2}{*}{ Model } & \multicolumn{2}{|c|}{$\begin{array}{c}\text { Unstandardized } \\
\text { Coefficients }\end{array}$} & \multirow{2}{*}{$\begin{array}{l}\text { Standardized } \\
\text { Coefficients } \\
\text { Beta }\end{array}$} & \multirow[t]{2}{*}{$\mathbf{t}$} & \multirow[t]{2}{*}{ Sig. } \\
\hline & B & Std. Error & & & \\
\hline (Constant) & 0,668 & 0,369 & & 1,810 & 0,077 \\
\hline $\begin{array}{c}\text { Kepuasan Kerja } \\
\text { (X) }\end{array}$ & 0,841 & 0,089 & 0,816 & 9,475 & 0,000 \\
\hline $\mathrm{R}^{2}$ & & & & & 0,666 \\
\hline F Hitung & & & & & 89,766 \\
\hline Sig. F & & & & & 0,000 \\
\hline
\end{tabular}

Hasil analisis jalur substruktural 1 seperti yang disajikan pada Tabel 7 . maka persamaan strukturalnya adalah sebagai berikut:

$$
Z=0,668-0,841 X
$$

Hasil analisis jalur substruktural 2 seperti yang disajikan pada Tabel 8, maka persamaan strukturalnya adalah sebagai berikut.

$$
\mathrm{Y}=5,556+(-0,238 \mathrm{X})+(-0,669 \mathrm{Z})+\mathrm{e}_{2}
$$

Berdasarkan model substruktur 1 dan substruktur 2, maka dapat disusun model diagram jalur akhir. Sebelum menyusun diagram jalur akhir, terlebih dahulu menghitung nilai standar error sebagai berikut.

$$
\begin{aligned}
& \mathrm{Pe}_{\mathrm{i}}=\sqrt{1-R i^{2}} \\
& \mathrm{Pe}_{1}=\sqrt{1-R 1^{2}}=\sqrt{1-0,666}=0,578 \\
& \mathrm{Pe}_{2}=\sqrt{1-R 1^{2}}=\sqrt{1-0,859}=0,375
\end{aligned}
$$


Tabel 8.

Hasil Analisis Jalur Persamaan Regresi 2

\begin{tabular}{|c|c|c|c|c|c|}
\hline \multirow[t]{2}{*}{ Model } & \multicolumn{2}{|c|}{$\begin{array}{c}\text { Unstandardized } \\
\text { Coefficients }\end{array}$} & \multirow{2}{*}{$\begin{array}{c}\text { Standardized } \\
\text { Coefficients } \\
\text { Beta }\end{array}$} & \multirow[t]{2}{*}{$\mathbf{t}$} & \multirow[t]{2}{*}{ Sig. } \\
\hline & B & Std. Error & & & \\
\hline (Constant) & 5,556 & 0,235 & & 23,594 & 0,000 \\
\hline $\begin{array}{c}\text { Kepuasan Kerja } \\
\text { (X) }\end{array}$ & $-0,238$ & 0,095 & $-0,247$ & $-2,519$ & 0,015 \\
\hline $\begin{array}{c}\text { Komitmen } \\
\text { Organisasional } \\
(\mathrm{Z})\end{array}$ & $-0,669$ & 0,092 & $-0,714$ & $-7,288$ & 0,000 \\
\hline $\mathrm{R}^{2}$ & & & & & 0,859 \\
\hline F Hitung & & & & & 133,883 \\
\hline Sig. F & & & & & 0,000 \\
\hline
\end{tabular}

Sumber: Data diolah, 2019

Berdasarkan perhitungan pengaruh error $\left(\mathrm{Pe}_{\mathrm{i}}\right)$ didapatkan hasil pengaruh error $\left(\mathrm{Pe}_{1}\right)$ sebesar 0,578 dan pengaruh error $\left(\mathrm{Pe}_{2}\right)$ sebesar 0,375. Hasil koefisien determinasi total adalah sebagai berikut.

$$
\begin{aligned}
\mathrm{R}^{2} \mathrm{~m} & =1-\left(\mathrm{Pe}_{1}\right)^{2}\left(\mathrm{Pe}_{2}\right)^{2} \ldots \ldots \\
& =1-(0,578)^{2}(0,375)^{2} \\
& =1-(0,578)^{2}(0,375)^{2} \\
& =1-(0,334)(0,141) \\
& =1-0,047 \\
& =0,953
\end{aligned}
$$

Nilai determinasi total sebesar 0,953 mempunyai arti bahwa sebesar 95,3 persen variasi turnover intention karyawan dipengaruhi oleh variasi kepuasan kerja dan variasi komitmen organisasional, sedangkan sisanya 4,7 persen dijelaskan oleh faktor lain yang tidak dimasukkan ke dalam model.

Hasil analisis pengaruh kepuasan kerja terhadap turnover intention diperoleh nilai Sig. $t$ sebesar 0,015 dengan nilai koefisien beta $-0,247$. Nilai Sig. $t$ $0,000 \leq 0,05$ mengindikasikan bahwa $\mathrm{H}_{0}$ ditolak dan $\mathrm{H}_{1}$ diterima. Hasil ini mempunyai arti bahwa kepuasan kerja berpengaruh negatif signifikan terhadap turnover intention.

Hasil analisis pengaruh komitmen organisasional terhadap turnover intention diperoleh nilai Sig. $\mathrm{t}$ sebesar 0,000 dengan nilai koefisien beta $-0,714$. Nilai Sig. t $0,000 \leq 0,05$ mengindikasikan bahwa $\mathrm{H}_{0}$ ditolak dan $\mathrm{H}_{1}$ diterima. Hasil ini mempunyai arti bahwa komitmen organisasional berpengaruh negatif signifikan terhadap turnover intention.

Hasil analisis pengaruh kepuasan kerja terhadap komitmen organisasional diperoleh nilai Sig. $\mathrm{t}$ sebesar 0,000 dengan nilai koefisien beta 0,816. Nilai Sig. $\mathrm{t}$ $0,000 \leq 0,05$ mengindikasikan bahwa $\mathrm{H}_{0}$ ditolak dan $\mathrm{H}_{1}$ diterima. Hasil ini mempunyai arti bahwa kepuasan kerja berpengaruh positif signifikan terhadap komitmen organisasional. 
Perhitungan pengaruh antar variabel dirangkum dalam Tabel 9. sebagai berikut:

Tabel 9.

Rangkuman Hasil Uji

\begin{tabular}{cccc}
\hline $\begin{array}{c}\text { Pengaruh } \\
\text { Variabel }\end{array}$ & $\begin{array}{c}\text { Pengaruh } \\
\text { Langsung }\end{array}$ & $\begin{array}{c}\text { Pengaruh Tidak Langsung Melalui } \\
\text { Kepuasan Kerja }(\mathbf{M})\left(\boldsymbol{\beta}_{1} \times \boldsymbol{\beta}_{2}\right)\end{array}$ & $\begin{array}{c}\text { Pengaruh } \\
\text { Total }\end{array}$ \\
\hline $\mathrm{X} \rightarrow \mathrm{Z}$ & 0,841 & - & 0,841 \\
$\mathrm{X} \rightarrow \mathrm{Y}$ & $-0,238$ & $-0,563$ & $-0,801$ \\
$\mathrm{Z} \rightarrow \mathrm{Y}$ & $-0,669$ & - & $-0,669$ \\
\hline
\end{tabular}

Sumber: Data diolah, 2019

Keterangan:

$\mathrm{X}=$ Kepuasan Kerja

$\mathrm{Z}=$ Komitmen Organisasional

$\mathrm{Y}=$ Turnover Intention

Uji Sobel merupakan alat analisis untuk menguji signifikansi dari hubungan tidak langsung antara variabel bebas dengan variabel terikat yang dimediasi oleh variabel mediator. Uji Sobel dirumuskan dan dihitung melalui aplikasi Microsoft Excel 2007. Bila nilai Z lebih besar dari 1,96 maka variabel mediator dinilai secara signifikan memediasi hubungan antara variabel terikat dan variabel bebas. Hasil Uji Sobel disajikan sebagai berikut.

$$
Z=\frac{a b}{\sqrt{b^{2} S a^{2}+a^{2} S b^{2}+S a^{2} S b^{2}}}
$$

Keterangan:

$$
\begin{aligned}
& \text { a } \quad=0,841 \\
& \mathrm{Sa}=0,089 \\
& \mathrm{~b} \quad=0,669 \\
& \mathrm{Sb}=0,092 \\
& Z=\frac{0,841 \times 0,669}{\sqrt{0,669^{2} 0,089^{2}+0,841^{2} 0,092^{2}+0,089^{2} 0,092^{2}}} \\
& Z=\frac{0,5626}{\sqrt{0,0035+0,0060+0,0001}} \\
& Z=\frac{0,5626}{\sqrt{0,0096}} \\
& Z=\frac{0,5626}{0,097972} \\
& \mathrm{Z}=5,7427=5,74
\end{aligned}
$$

Berdasarkan hasil perhitungan menunjukkan bahwa hasil tabulasi $\mathrm{Z}=5,74$ > 1,96 yang berarti variabel mediator yakni komitmen organisasional dinilai secara signifikansi memediasi hubungan antara kepuasan kerja terhadap turnover intention karyawan. 
Pengujian hipotesis pada pengaruh kepuasan kerja terhadap turnover intention menunjukkan bahwa kepuasan kerja berpengaruh negatif dan signifikan terhadap turnover intention. Hal ini menjelaskan bahwa semakin tinggi tingkat kepuasan karyawan terhadap pekerjaan itu sendiri, gaji, kesempatan promosi, pengawasan atasan dan rekan kerja maka akan menurunkan keinginan karyawan PT Tiara Cipta Nirwana untuk meninggalkan perusahaan.

Hasil penelitian ini mendukung penelitian yang dilakukan Alniaçik et al. (2013); Huang dan Su (2016); Tripath dan Pandey (2017) yang menjelaskan bahwa meningkatnya kepuasan kerja karyawan maka akan menurunkan keinginan karyawan untuk keluar dari perusahaannya. Begitu pula dengan penelitian yang dilakukan Saeed et al. (2014) yang menyatakan ada hubungan negatif antara kepuasan kerja dengan turnover intention, semakin tinggi selisih antara ekspektasi karyawan terhadap imbalan yang akan diterima dengan imbalan yang benar-benar diterima maka hasilnya akan meningkatkan turnover intention karyawan.

Pengujian hipotesis pada pengaruh komitmen organisasional terhadap turnover intention menunjukkan bahwa komitmen organisasional berpengaruh negatif dan signifikan terhadap turnover intention. Hal ini menjelaskan bahwa semakin tinggi komitmen organisasional akan menurunkan keinginan karyawan PT Tiara Cipta Nirwana untuk meninggalkan perusahaan.

Hasil penelitian ini didukung dengan hasil penelitian yang dilakukan (Islam et al. (2015) dan Wong dan Wong (2017) bahwa affective commitment berpengaruh negatif dan signifikan terhadap turnover intention. Kusuma dan Mujiati (2017) menyatakan bahwa komitmen organisasional memiliki pengaruh negatif dan signifikan terhadap turnover intention, berarti apabila karyawan memiliki keinginan berkorban yang tinggi untuk memberikan kontribusinya bagi perusahaan maka tingkat keinginan untuk keluar dari perusahaan akan menurun.

Pengujian hipotesis pada pengaruh kepuasan kerja terhadap komitmen organisasional menunjukkan bahwa kepuasan kerja berpengaruh positif dan signifikan terhadap komitmen organisasional. Hal ini menjelaskan bahwa semakin tinggi tingkat kepuasan karyawan terhadap pekerjaan itu sendiri, gaji, kesempatan promosi, pengawasan atasan dan rekan kerja maka akan meningkatkan komitmen organisasional pada karyawan PT Tiara Cipta Nirwana.

Hasil penelitian ini mendukung penelitian yang dilakukan Babalola (2016) yang menjelaskan bahwa kepuasan kerja berpengaruh positif terhadap komitmen organisasi. Yücel (2012); Tarigan dan Ariani (2015) menyatakan bahwa kepuasan kerja berperngaruh positif dan signifikan terhadap komitmen organisasional, meningkatnya kepuasan yang dirasakan karyawan terhadap pekerjaannya, maka akan meningkatkan komitmen organisasionalnya.

Hasil pengujian hipotesis menunjukkan bahwa komitmen organisasional memediasi pengaruh kepuasan kerja terhadap turnover intention. Berdasarkan pengujian pengaruh langsung menunjukkan kepuasan kerja berpengaruh positif dan signifikan terhadap komitmen organisasional, kepuasan kerja berpengaruh negatif dan signifikan terhadap turnover intention, serta komitmen organisasional berpengaruh negatif dan signifikan terhadap turnover intention, sehingga dapat disimpulkan bahwa komitmen organisasional secara parsial memediasi pengaruh 
I Wayan Bagus Satya Utama, Peran Komitmen Organisasional...

kepuasan kerja terhadap turnover intention pada karyawan PT Tiara Cipta Nirwana.

Hasil penelitian ini didukung oleh penelitian yang dilakukan Tarigan dan Ariani (2015), dalam penelitiannya menjelaskan bahwa multidimensi dari komitmen organisasional yaitu: affective commitment, continuance commitment, dan normative commitment memediasi pengaruh kepuasan kerja terhadap turnover intention. Menurut Rekha and Kamalanabhan (2010) menjelaskan bahwa yang dapat membantu karyawan meningkatkan komitmen karyawan terhadap organisasi adalah dengan meningkatkan kepuasan kerja karyawan, ketika komitmen terhadap organisasi meningkat, niat karyawan untuk berhenti dari tempat kerjanya akan menurun, sehingga dapat dikatakan komitmen organisasional memediasi hubungan kepuasan kerja terhadap turnover intention.

Hasil penelitian ini menunjukkan bahwa kepuasan kerja dan berpengaruh secara langsung terhadap turnover intention, maupun secara tidak langsung melalui komitmen organisasional. Hal ini menjelaskan bahwa yang dapat membantu karyawan meningkatkan komitmen karyawan terhadap organisasi adalah dengan meningkatkan kepuasan kerja karyawan, ketika komitmen terhadap organisasi meningkat, niat karyawan untuk berhenti dari tempat kerjanya akan menurun.

Temuan penelitian ini memberikan implikasi terhadap strategi pengembangan sumber daya manusia di PT Tiara Cipta Nirwana untuk lebih memperhatikan indikator-indikator kepuasan kerja dan komitmen organisasional. Terutama yang harus diperhatikan kepuasan terhadap pekerjaan itu sendiri dengan cara perusahaan harus memperhatikan kemampuan karyawan agar sesuai dengan beban pekerjaan yang ada karena kepuasan terhadap pekerjaan itu sendiri memiliki nilai rata-rata tertinggi pada variabel kepuasan kerja. Sedangkan untuk variabel komitmen organisasional yang menjadi perhatian utama adalah affective commitment dengan cara membuat karyawan merasa senang untuk menghabiskan karir di perusahaan sehingga karyawan merasa bangga menjadi bagian dari perusahaan dan bangga akan perusahaan tempatnya bekerja. Sehingga penelitian ini diharapkan dapat digunakan sebagai bahan pertimbangan para pengambil keputusan dalam menekan tingkat turnover karyawan dengan cara menurunkan turnover intention karyawan.

Secara teoritis, Hasil penelitian ini jika dikaitkan dengan Traditional Turnover Theory, maka dapat dikatakan perusahaan harus memperhatikan kepuasan kerja karyawan sehingga nantinya karyawan karyawan memiliki komitmen organisasional atau keinginan berkorban untuk memberikan kontribusinya bagi perusahaan dan berakhir pada rendahnya niat karyawan untuk meninggalkan perusahaan. Hasil penelitian ini memberikan implikasi bahwa kepuasan kerja dapat mempengaruhi turnover intention secara tidak langsung. Hubungan tidak langsung bisa terjadi melalui peran mediasi komitmen organisasional, dimana karyawan tidak akan meninggalkan perusahaan jika memiliki keinginan berkorban yang tinggi untuk memberikan kontribusinya bagi perusahaan atau dapat dikatakan memiliki komitmen yang tinggi terhadap perusahaannya dan cenderung karyawan yang memiliki komitmen yang tinggi didukung oleh kepuasan kerja yang tinggi. Karena karyawan yang tidak puas 
terhadap pekerjaannya tidak memiliki komitmen organisasional yang tinggi atau dikatakan tidak memiliki keinginan berkorban untuk memberikan kontribusinya bagi perusahaan dan cenderung memiliki niat untuk keluar dari perusahaan.

Penelitian ini memiliki beberapa keterbatasan yaitu peneliti mengumpulkan data menggunakan kuesioner yang disebarkan melalui pihak human capital section dengan alasan operasional dari perusahaan, sehingga peneliti tidak mendampingi secara langsung proses pengisian kuesioner. Penelitian ini hanya dilakukan pada karyawan PT Tiara Cipta Nirwana dengan melibatkan 47 orang sebagai responden, sehingga tidak bisa menggeneralisir kondisi perusahaan lain. Variabel-variabel yang digunakan pada penelitian ini hanya terbatas pada variabel kepuasan kerja dan komitmen organisasional dalam mengukur turnover intention. Diharapkan pada penelitian selanjutnya dapat mengembangkan lagi variabel yang diteliti mengingat terdapat banyak variabel-variabel lain yang mempengaruhi turnover intention.

\section{SIMPULAN}

Berdasarkan permasalahan penelitian, tujuan, hipotesis dan hasil pembahasan penelitian pada bab sebelumnya, maka dapat disimpulkan bahwa kepuasan kerja berpengaruh negatif dan signifikan terhadap turnover intention. Hal ini mengandung makna, bahwa semakin tinggi tingkat kepuasan kerja karyawan maka semakin rendah niat karyawan keluar dari perusahaan, begitu pula sebaliknya.

Komitmen organisasional berpengaruh negatif dan signifikan terhadap turnover intention. Hal ini menunjukkan bahwa semakin tinggi tingkat komitmen organisasional karyawan maka semakin rendah niat karyawan keluar dari perusahaan, begitu pula sebaliknya. Kepuasan kerja berpengaruh positif dan signifikan terhadap komitmen organisasional. Hal ini mengandung makna, bahwa semakin tinggi tingkat kepuasan kerja karyawan maka semakin tinggi pula komitmen organisasional karyawan tersebut. Komitmen organisasional secara parsial memediasi pengaruh kepuasan kerja terhadap turnover intention. Hal ini menunjukkan bahwa pengaruh kepuasan kerja terhadap turnover intention diperkuat dengan masuknya komitmen organisasional sebagai mediator.

PT Tiara Cipta Nirwana hendaknya lebih memperhatikan kesempatan promosi karyawan dengan cara memberikan sosialisasi terkait standar-standar yang harus dicapai untuk memperoleh promosi sehingga terciptanya transparansi terhadap kesempatan promosi antara karyawan dengan perusahaan, agar dapat meningkatkan kepuasan kerja karyawan nantinya akan berdampak pada meningkatnya komitmen karyawan serta dapat menurunkan niat karyawan untuk meninggalkan perusahaan. Karena indikator "kesempatan promosi" merupakan indikator dengan nilai rata-rata terendah pada deskripsi variabel kepuasan kerja. PT Tiara Cipta Nirwana hendaknya lebih meningkatkan kepuasan kerja karyawan agar karyawan merasa rugi apabila keluar dari perusahaan, menganggap bekerja pada perusahaan merupakan suatu kebutuhan dan merupakan kesempatan terbaik. 
Hal tersebut dapat meningkatkan komitmen organisasional yang nantinya akan menurunkan niat karyawan untuk meninggalkan perusahaan.

\section{REFERENSI}

Alniaçik, E. et al. (2013) 'Does person-organization fit moderate the effects of affective commitment and job satisfaction on turnover intentions?', Procedia - Social and Behavioral Sciences, 99, pp. 274-281. doi: 10.1016/j.sbspro.2013.10.495.

Andini, O. P., Sunuharyo, B. S. and Utami, H. N. (2018) 'Pengaruh kepuasan kerja terhadap stres kerja dan turnover intention karyawan (Studi pada Karyawan PT Indolakto FactoryPandaan)', Jurnal Administrasi Bisnis, 54(1).

Azeem, S. M. (2010) 'Job Satisfaction and Organizational Commitment among Employees in the Sultanate of Oman', Journal of Psychology, 1(4), pp. 295-299. doi: 10.4236/psych.2010.14038.

Azeez, R. O., Jayeoba, F. I. and Adeoye, A. O. (2016) 'Job satisfaction, turnover intention and organizational commitment', BVIMSR's Journal of Management Research, 8(2), pp. 102-114.

Babalola, S. S. (2016) 'The effect of leadership style, job satisfaction and employee-supervisor relationship on job performance and organizational commitment', The Journal of Applied Business Research, 32(3), pp. 935947.

Busari, A. H. et al. (2017) 'Analytical cognitive style moderation on promotion and turnover intention', Journal of Management Development, 36(3), pp. 438-464. doi: 10.1108/JMD-12-2015-0184.

Fahrizal and Utama, I. W. M. (2017) 'Pengaruh Persepsi Dukungan Organisasi terhadap Komitmen Organisasional dan Turnover Intention Karyawan Hotel Kajane Mua Ubud', E-Jurnal Manajemen Universitas Udayana, 6(10), pp. 5405-5431.

Hidayat, A. S. (2018) 'Pengaruh Kepuasan Kerja Terhadap Komitmen Organisasi Dan Turnover Intention', Jurnal Manajemen dan Pemasaran Jasa, 11(1), pp. 51-66. doi: 10.25105/jmpj.v11i1.2516.

Huang, W. R. and Su, C. H. (2016) 'The mediating role of job satisfaction in the relationship between job training satisfaction and turnover intentions', Industrial and Commercial Training, 48(1), pp. 42-52. doi: 10.1108/ICT-04-2015-0029. 
Islam, T., Ahmed, I. and Ahmad, U. N. B. U. (2015) 'The influence of organizational learning culture and perceived organizational support on employees' affective commitment and turnover intention', Nankai Business Review International, 6(4), pp. 417-431. doi: 10.1108/NBRI01-2015-0002.

Kamanjaya, I. G. H., Supartha, W. G. and Dewi, I. A. M. (2017) 'Pengaruh servant leadership terhadap komitmen organisasional dan kinerja pegawai (Studi pada Pegawai Negeri Sipil di RSUD Wangaya Kota Denpasar)', E-Jurnal Ekonomi dan Bisnis Universitas Udayana, 6(7), pp. 2731-2760. doi: 10.24843/eeb.2017.v06.i07.p05.

Kusuma, K. I. P. and Mujiati, N. W. (2017) 'Pengaruh Perceived Organizational Support Dan Komitmen Organisasional Terhadap Turnover Intention Karyawan Di Hotel Alila Ubud', E-Jurnal Manajemen Universitas Udayana, 6(10), pp. 5748-5774.

Mira, W. S. and Margaretha, M. (2012) 'Pengaruh servant leadership terhadap komitmen organisasi dan organization citizenship behavior', Jurnal Manajemen, 11(2), pp. 189-206.

Mohamed, S. and Anisa, H. (2012) 'Relationship Between Organizational Commitment and Organizational Citizenship Behavior', The IUP Journal of Organizational Behavior, 9(3). doi: 10.5829/idosi.wjmbs.2013.1.1.1104.

Novarinda, R. and Iqbal, M. (2017) 'Pengaruh keterlibatan kerja dan iklim kerja terhadap komitmen (Studi pada Rumah Sakit Umum Daerah Sidoarjo)', Jurnal Administrasi Bisnis, 53(2), pp. 56-65.

Pariatiningsih, C. I. V. and Utama, I. W. M. (2015) 'Pengaruh keadilan distributif dan komitmen organisasi terhadap turnover intention pada maxi hotel, restaurant and spa di legian', E-Jurnal Manajemen Universitas Udayana, 4(11), pp. 3508-3536.

Perryer, C. et al. (2010) 'Predicting turnover intentions the interactive effects of organizational commitment and perceived organizational support', Management Research Review, 33(9), pp. 911-923. doi: 10.1108/01409171011070323.

Rekha, S. and Kamalanabhan, T. J. (2010) 'A three-dimensional analysis of turnover intention among employees of ITES/BPO sector', South Asian Journal of Management, 17(3).

Rismawan, P. A. E., Supartha, W. G. and Yasa, N. N. K. (2014) 'Peran Mediasi Komitmen Organisasional Pada Pengaruh Stress Kerja Dan Kepuasan 
I Wayan Bagus Satya Utama, Peran Komitmen Organisasional...

Kerja Terhadap Intensi Keluar Karyawan', E-Jurnal Ekonomi dan Bisnis Universitas Udayana, 3(8), pp. 424-441.

Robbins, S. P., Timothy, A. and Judge (2009) Perilaku Organisasi, Edisi 12, Jakarta: Salemba Empat.

Saeed, I. et al. (2014) 'The relationship of turnover intention with job satisfaction, job performance, Leader member exchange, Emotional intelligence and organizational commitment', 4(2), pp. 242-256. doi: 10.5296.

Salleh, R., Sivadahasan, N. M. and Haryanni, H. (2012) 'International Journal of Social, Behavioral, Educational, Economic, Business and Industrial Engineering', 6(12).

Satrio, M. I. B. and Surya, I. B. K. (2018) 'The Role Of Organizational Commitment In Mediating The Effect Of Job Satisfaction And Perceived Organizational Support On Turnover Intention.', International Journal of Social Science and Humanities Research, 6(4), p. 2018.

Satwari, T., Musadieq, M. A. and Afrianty, T. W. (2016) 'Pengaruh komitmen organisasional terhadap turnover intention (Survei pada Karyawan Hotel Swiss-Belinn Malang)', Jurnal Administrasi Bisnis, 40(2), pp. 177-186.

Soleimani, A G. and Einolahzadeh, H. (2017) 'The mediating effect of leadermember exchange in relationship with emotional intelligence, job satisfaction, and turnover intention', Cogent Business and Management. Cogent, 4. doi: 10.1080/23311975.2017.1419795.

Sugiyono (2017) 'Pendekatan Kuantitatif, Kualitatif, Kombinasi, R\&D dan Penelitian Evaluasi', in Metodelogi Penelitian.

Tarigan, V. and Ariani, D. W. (2015) 'Empirical Study Relations Job Satisfaction, Organizational Commitment, and Turnover Intention', Advances in Management and Applied Economics, 5(2), pp. 21-42..

Tnay, E. et al. (2013) 'The Influences of Job Satisfaction and Organizational Commitment on Turnover Intention', Procedia - Social and Behavioral Sciences. Elsevier B.V., 97, pp. 201-208. doi: 10.1016/j.sbspro.2013.10.223.

Tripathi, P. and Pandey, M. K. (2017) 'Examining the Relationship between Work-Family Conflict, Job Satisfaction and Employee's Turnover Intention', Journal of Psychosocial Research, 12(2), p. 451.

Valaei, N. and Rezaei, S. (2016) 'Job satisfaction and organizational commitment An empirical investigation among ICT-SMEs', Management Research 
Review, 39(12), pp. 1663-1694. doi: 10.1108/MRR-09-2015-0216.

Wong, Y. W. and Wong, Y. T. (2017) 'The effects of perceived organisational support and affective commitment on turnover intention: A test of two competing models', Journal of Chinese Human Resource Management, 8(1), pp. 2-21. doi: 10.1108/JCHRM-01-2017-0001.

Yücel, I. (2012) 'Examining the relationships among job satisfaction, organizational commitment, and turnover intention: an empirical study', International Journal of Business and Management, 7(20), pp. 44-58. doi: 10.5539/ijbm.v7n20p44.

Zhao, E. and Liu, L. (2010) 'Comments on Development of Job Embeddedness about Study on Turnover and Exploration into Application in Enterprises', Asian Social Science, 6(6), pp. 63-72. doi: 10.5539/ass.v6n6p63. 